\title{
MEDIA VIDEO PROFILE PENUNJANG PROMOSI DAN INFORMASI PADA SMK HARAPAN JAYA KOTA TANGERANG
}

\author{
Ryan Renaldi ${ }^{1}$ \\ Ani Fitriyani ${ }^{2}$ \\ Gian Rizki Illahi ${ }^{3}$ \\ STMIK Raharja Jurusan Teknik Informatika ${ }^{1,2,3}$ \\ Jl. Jendral Sudirman No. 40, Modern Cikokol, Tangerang ${ }^{1,2,3}$ \\ Email : ryan.renaldi@raharja.info ${ }^{1)}$, ani.fitriyani@raharja.info ${ }^{2)}$, gian@ @aharja.info
}

\begin{abstract}
ABSTRAK
Informasi menjadi hal penting karena dengan informasi seseorang akan mendapat hal yang ingin diketahuinya. Penyebaran informasi tersebar melalui media cetak ataupun media elektronik, dari media itulah masyarakat dapat memperoleh informasi. Dalam hal ini SMK Harapan Jaya belum memiliki sebuah media berbentuk video sebagai penunjang promosi dan informasi. Untuk memecahkan permasalahan mengenai pemahaman terhadap SMK Harapan Jaya khususnya mengenai promosi dan informasi, penulis mengajukan perancangan sebuah media profile sekolah berbasis video bertujuan untuk memperkenalkan identitas sekolah, keseluruhan promosi, dan informasi yang terkait di dalamnya serta mengenai kepentingan promosi dan informasi. Dalam mempersiapkan produksi media video profile tersebut digunakan metodologi yang berdasarkan hasil observasi sesuai kebijakan sekolah sehingga mendapatkan data dukung laporan penelitian sekaligus digunakan pijakan dalam menentukan topik penelitian sehingga penyajian promosi dan informasi lebih efektif, akurat, dan menarik dari segi tampilan maupun isi konten. Editing untuk video menggunakan Adobe Premier CS3, Adobe Photoshop CS. Sebagai pedoman dalam produksi media berbasis video digunakan konsep perancangan produksi yang disebut Konsep Produksi Media. Pada konsep tersebut terdapat tahapan Preproduction membuat ide dan narasi, tahapan Production pengambilan gambar dan editing tahapan Postproduction menyalurkan video yang sudah jadi ke youtube. Dari hasil rancangan media video profile tersebut dapat memberikan kesimpulan manfaat kepada masyarakat dan calon siswa siswi yang akan masuk ke SMK Harapan Jaya agar lebih mengenal tentang detail profile yang dimiliki SMK Harapan Jaya.
\end{abstract}

Kata kunci : Video Profile, Informasi, dan Promosi.

\begin{abstract}
Development of science and information makes a variety of activities and life sehari-hari of the information gained from the media, both print and electronic media. The role of information technology and multimedia are also not to miss, a variety of information offered by the form of multimedia that can create interactive and informative presentation by combining text, audio, video, animation and graphics used for competitive advantage Development education grew rapidly, causing a growing number of facilities and advantages that should be promoted to compete, especially at SMK Yuppentek 4 Ciledug Tangerang. The purpose of this research is to design-based audio visual media in order to be an effective appeal, especially in the delivery of information and promotions regarding things - things that are related to the overall CMS Yuppentek 4 Ciledug Tangerang. SMK Yuppentek 4 Ciledug Tangerang is located in Tangerang. Existing problems,
\end{abstract}


namely the medium used by the SMK SMK Yuppentek 4 Ciledug Tangerang was a print media, in general the community more receptive of information via media interactive and communicative, so CMS Yuppentek 4 Ciledug Tangerang requires video media profile as a media of supporting information and promotion on the show to prospective students and students of SMK Yuppentek 4 Ciledug Tangerang, or as a media information to the public, so the design of video media profile that displays the entire scope, advantages and facilities belonging to SMK Yuppentek 4 Ciledug Tangerang, can be a solution in solving problems in media promotion and information. With this author makes research with the title "VIDEO PROFILE OF SUPPORTING MEDIA PROMOTION AND INFORMATION ON SMK HARAPAN JAYA CITY TANGERANG".

Keywords : Promotion, Audio Visual, Video Profile.

\section{PENDAHULUAN}

Perkembangan ilmu pengetahuan dan informasi membuat berbagai aktifitas dan kehidupan sehari-hari tidak lepas dari informasi yang didapat baik dari media cetak maupun media elektronik. Peranan teknologi informasi dan multimedia juga tidak ketinggalan, berbagai informasi ditawarkan dengan bentuk multimedia yang dapat menciptakan presentasi interaktif dan informatif dengan mengkombinasikan teks, audio, video, animasi dan grafik yang digunakan untuk keunggulan bersaing.

Dengan semakin berkembangnya teknologi informasi maka kebutuhan informasi pelaku pendidikan dan masyarakat secara otomatis meningkat dari segi kuantitas dan kualitas sehingga diperlukan penguasaan pengetahuan tentang teknologi informasi. Teknologi informasi menawarkan berbagai kemudahan yang dapat digunakan sebagai media informasi kepada masyarakat luas khususnya dalam dunia pendidikan. Peran teknologi informasi khususnya teknologi multimedia sangat berpengaruh karena dengan penyampaian menggunakan teks, audio, foto, video dan animasi yang didesain secara khusus akan membuat masyarakat tertarik untuk mengetahui isi dan berbagai informasi yang ada didalamnya.

SMK Harapan Jaya Kota Tangerang didirikan pada tanggal 19 Oktober 2000 oleh Yayasan Al Ittihad Harapan Jaya yang beralamat di J1.H. Mansyur no.25 Gondrong Cipondoh Kota Tangerang dengan No. SK Ijin Pendirian : 2389/102.I/Kep/OT/2000 yang dikeluarkan oleh Kanwil Departemen Pendidikan dan Kebudayaan Propinsi Jawa Barat. SMK Harapan Jaya Kota Tangerang memiliki 4 pilihan jurusan, yaitu : jurusan Akuntansi, jurusan Administrasi Perkantoran, Jurusan Teknik Komputer Jaringan, dan Jurusan Multimedia.

Kurikulum SMK Harapan Jaya Kota Tangerang mengacu pada peraturan Menteri Pendidikan Nasional RI No.22 tahun 2006 tentang standar isi, No.23 tahun 2006 tentang standar kompentensi Lulusan, No.24 tahun 2006 tentang ketentuan pelaksanaannya serta berpedoman pada panduan penyusunan kurikulum tingkat satuan pendidikan jenjang pendidikan dasar dan menengah yang diterbitkan oleh Badan Standar Nasional Pendidikan (BNSP). Kurikulum SMK Harapan Jaya Kota Tangerang dikembangkan dengan memperhatikan kebutuhan peserta didik, kondisi lingkungan serta memperhatikan kebutuhan tenaga kerja yang ada pada dunia usaha atau dunia industry di wilayah Tangerang. 


\section{RUMUSAN MASALAH}

masalah mengenai informasi tentang SMK Yuppentek 4 Ciledug Tangerang, dapat ditarik kesimpulan bahwa para calon siswa dan siswi belum mengetahui dengan jelas tentang profile SMK Harapan Jaya Kota Tangerang, karena dengan menggunakan media cetak. Informasi dan cara penyampaiannya saat ini belum efektif.

Media video profile dinilai lebih efektif karena manusia dapat mengingat sebanyak $80 \%$ apa yang dilihat, didengar dan dialaminya secara bersamaan dan karna video dapat menarik perhatian masyarakat serta calon siswa dan siswi SMK Harapan Jaya Kota Tangerang.

\section{LANDASAN TEORI Pengertian Media}

saluran penyampaian pesan komersial kepada khalayak sasaran atau dapat dikatakan salah satu komunikasi periklanan yang dilakukan melalui saluran media tertentu, seperti televisi, surat kabar, majalah, radio, buku profile, papan iklan, pos langsung, petunjuk penjualan, selebaran, pengantar penawaran dan alat peraga ${ }^{[5]}$.

\section{Konsep Dasar Video Profile}

profile perusahaan (corporate profile) merupakan video yang diproduksi untuk keperluan tertentu, misalnya memperkenalkan suatu perusahaan tertentu untuk disebarluaskan ke publik, selain itu sering dipakai sebagai sarana pendukung dalam suatu presentasi perusahaan atau kelompok tertentu.

\section{Konsep Dasar Promosi dan Informasi Pengertian Promosi}

promosi merupakan salah satu faktor penentu keberhasilan suatu program pemasaran. Betapapun berkualitasnya suatu produk, bila konsumen belum pernah mendengarnya dan tidak yakin produk itu akan berguna bagi mereka, maka mereka tidak akan pernah membelinya. Pentingnya promosi dapat digambarkan lewat perumpamaan bahwa pemasaran tanpa promosi dapat diibaratkan seorang pria berkaca mata hitam yang dari tempat gelap pada malam kelam mengedipkan matanya pada seorang gadis cantik di kejauhan.

pada hakikatnya promosi adalah suatu bentuk komunikasi pemasaran. Yang dimaksud dengan komunikasi pemasaran adalah aktivitas pemasaran yang berusaha menyebarkan informasi, mempengaruhi atau membujuk dan mengingatkan pasar sasaran atas perusahaan dan produknya agar bersedia menerima, membeli dan setia pada produk yang ditawarkan perusahaan yang bersangkutan ${ }^{[4]}$.

\section{Konsep Dasar Informasi}

informasi adalah data yang telah diolah menjadi sebuah bentuk yang lebih berarti bagi penerimanya, dan bermanfaat dalam mengambil sebuah keputusan.

informasi (information) dapat didefinisikan sebagai berikut: "Informasi adalah data yang diolah menjadi bentuk yang lebih berguna dan lebih berarti bagi yang menerimannya, informasi disebut juga data yang diproses atau data yang memiliki $\operatorname{arti}^{[8]}$. 


\section{Tahapan Produksi Audio Visual}

\section{Pra Produksi}

Pra produksi adalah tahapan sebelum diproduksi secara nyata ${ }^{[3]}$.

\section{Produksi}

Produksi adalah tahapan pengambilan data yang dibutuhkan sesuai script dan storyboard. Disini crew dan actor banyak berkomunikasi dilapangan produksi.

\section{Pasca Produksi}

Pasca Produksi adalah mengolah data - data yang diambil di tahap produksi, sehingga bisa menjadi bahan jadi atau final yang siap untuk diedarkan.

\section{Multimedia Audio Visual Dan Broadcasting \\ Definisi Multimedia}

Multimedia adalah penggunaan komputer untuk menampilkan teks, grafik, video, animasi dan suara dalam bentuk terpadu ${ }^{[2]}$.

\section{Definisi Audio Visual}

perkembangan teknologi dunia audio visual telah banyak mewarnai kehidupan manusia dari berbagai aspek kehidupan.

\section{Definisi Broadcasting}

Broadcasting adalah kegiatan dalam cara menyampaikan pesan, ide, hasrat, kepada khalayak dengan menggunakan fasilitas frequency, dengan kata lain dunia broadcasting adalah merupakan suatu kegiatan penyiaran yang dilakukan oleh seorang penyiar ${ }^{[1]}$.

\section{Pengertian Sinopsis}

Sinopsis adalah ringkasan cerita media periklanan atau film, merupakan bentuk atau pendekatan dari sebuah periklanan atau film dengan tetap memperhatikan unsur-unsur pencerminan dari sebuah periklanan atau film tersebut ${ }^{[6]}$.

\section{Pengertian Storyboard}

Story Board adalah rangkaian gambar ilustrasi yang berusaha menjelaskan bahasa tulisan scenario kedalam bahasa visual ${ }^{[7]}$.

\section{Preproduction}

Untuk Preproduction adalah step atau langkah dimana dimulainya ide, perencanaan dan persiapan dari Konsep Produksi MAVIB. Ada tujuh langkah Preproduction dalam Konsep Produksi MAVIB, dimulai dari Ide yang dituangkan secara sistematis, lalu diikuti dengan pembuatan sinopsis, Script Writting dan Storyboard.Dua tahapan terakhir adalah pemilihan pemain dan crew dan Setting Alat. Semua tahapan yang ada harus sesuai TimeSchedule yang ditetapkan. Untuk lebih jelasnya di ilustrasikan pada bagan berikut ini : 


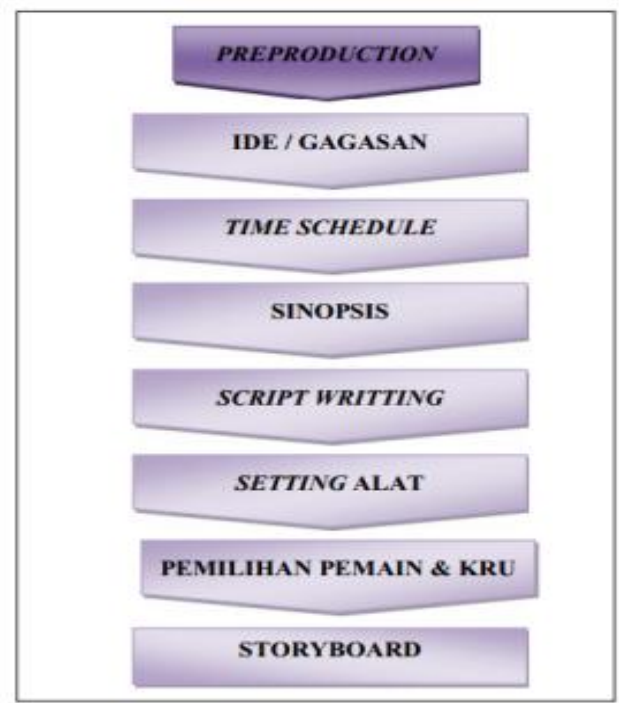

Gambar 1. Preproduction

\section{Time Schedule}

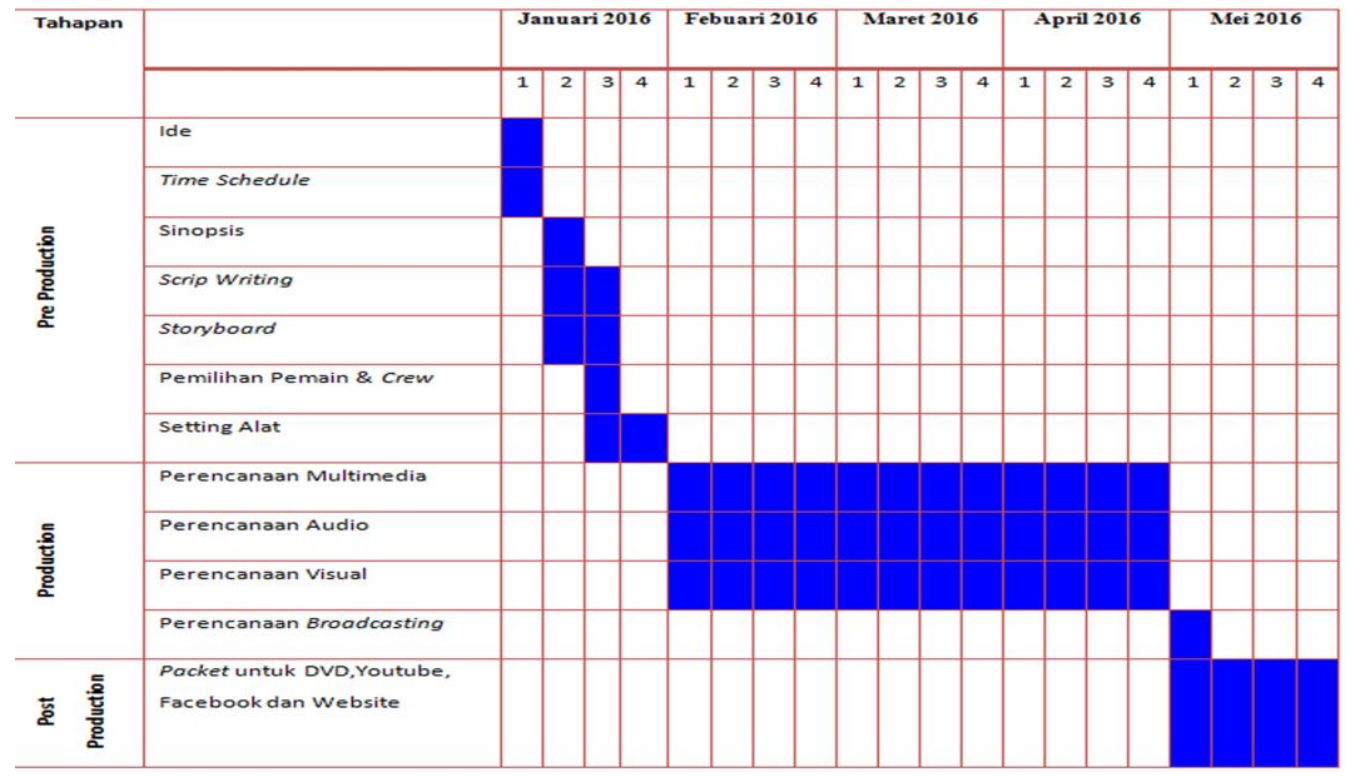

Gambar 2. Time Schedule

\section{Storyboard}

Scene 1

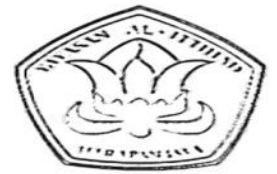

Gambar 3. Logo SMK Harapan Jaya

Bumper Opening logo SMK

Harapan Jaya Kota Tangerang 
Scene 2

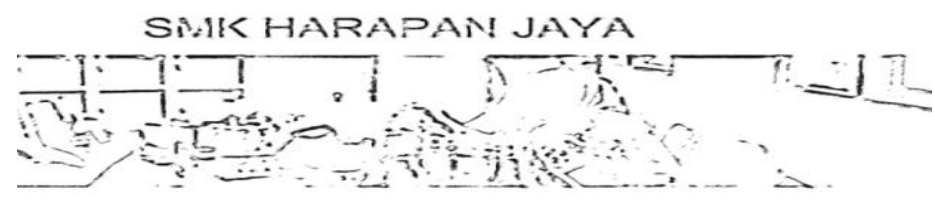

Gambar 4: Slide video SMK Harapan Jaya

Tampilan slide video SMK Harapan Jaya

\section{Scene 3}

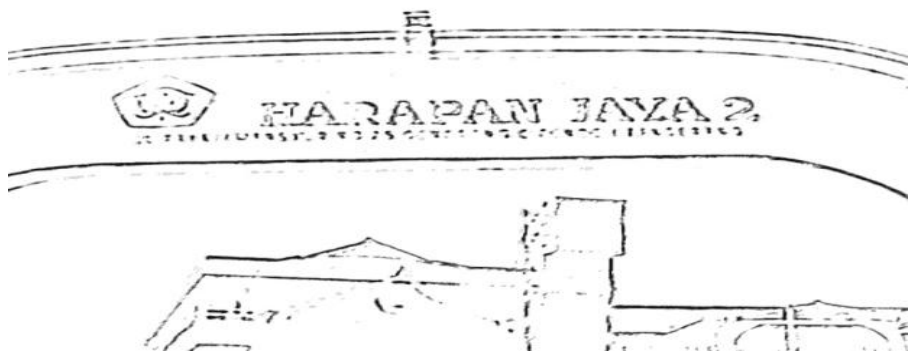

Gambar 5: Video papan nama sekolah

(Full Shoot) (MLS) / EXT

Papan Nama

\section{Scene 4}

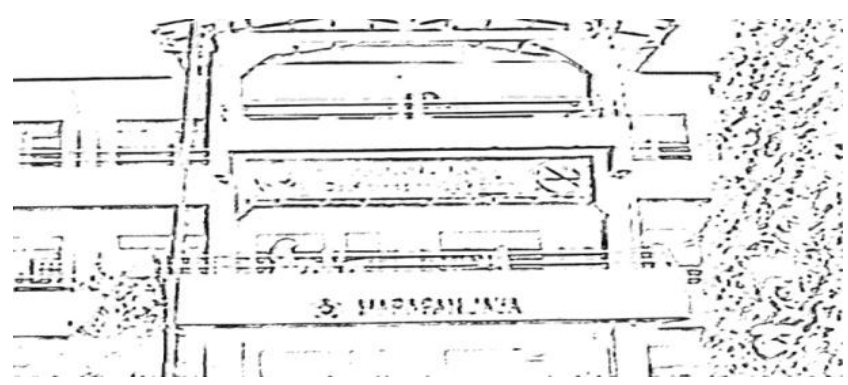

Gambar 6: Video gedung Sekolah

(Full Shoot) / EXT

Gedung Sekolah

Scane 5

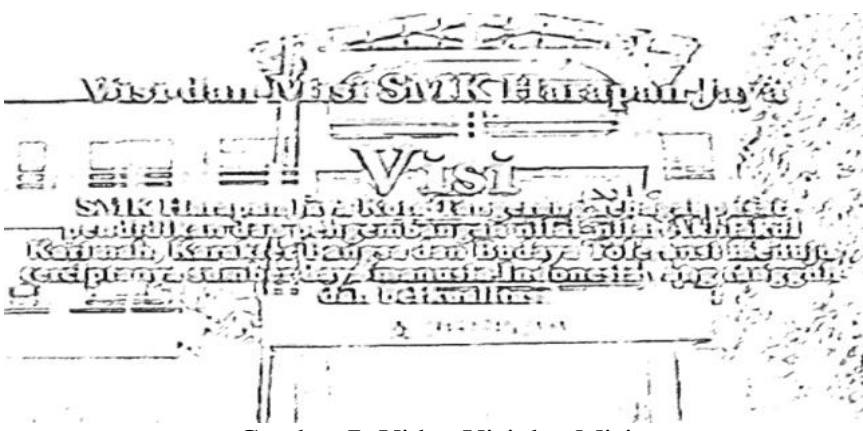

Gambar 7: Video Visi dan Misi

Visi Misi SMK Harapan Jaya 


\section{Scene 6}

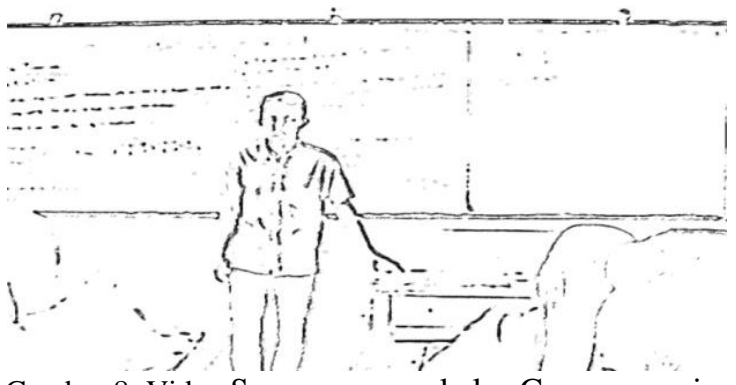

Gambar 8: Video Suasana ruang kelas Guru mengajar

(Full Shoot)/ INT

Suasana ruang kelas Guru mengajar

Scene 7

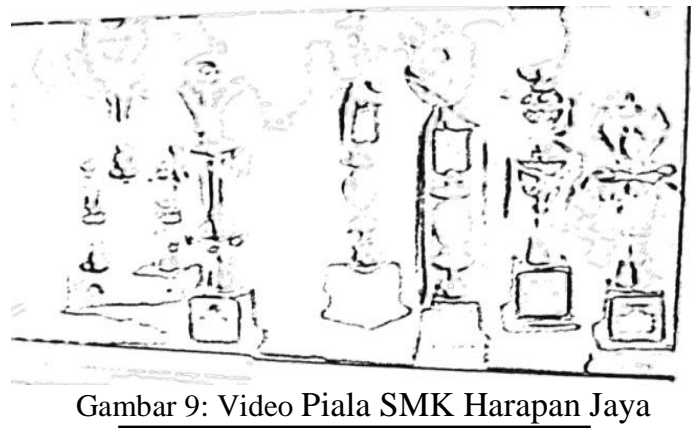

(medium shoot)/ INT

Piala SMK Harapan Jaya

Scene 8

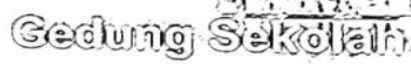

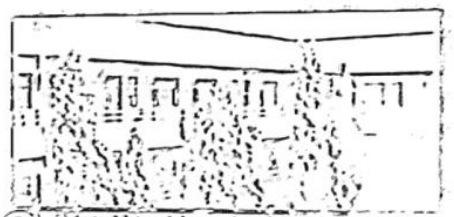

Gambar 10: Video Sarana dan Prasarana SMK Harapan Jaya

Sarana dan Prasarana SMK

Harapan Jaya

\section{Scene 9}

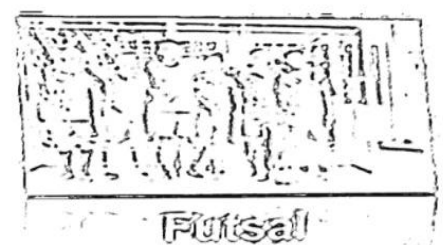

Gambar 11: Video Ekstrakulikuler SMK Harapan Jaya

Ekstrakulikuler SMK Harapan

Jaya 
Scene 10

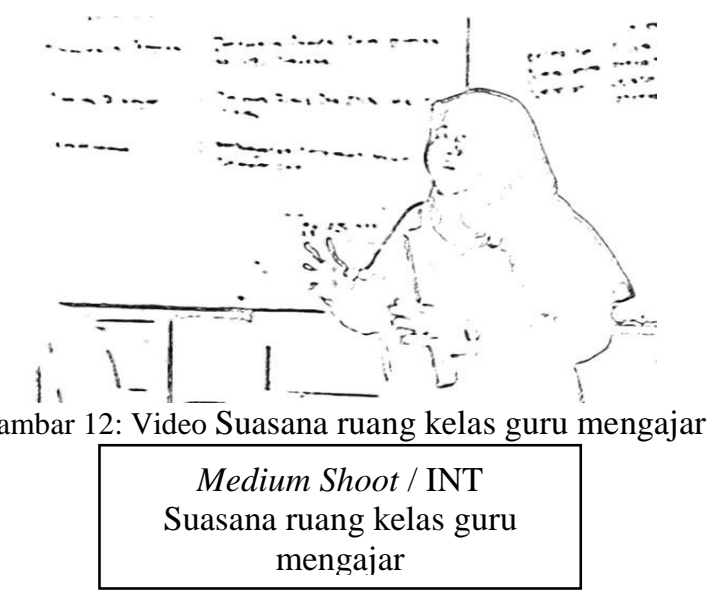

Scene 11

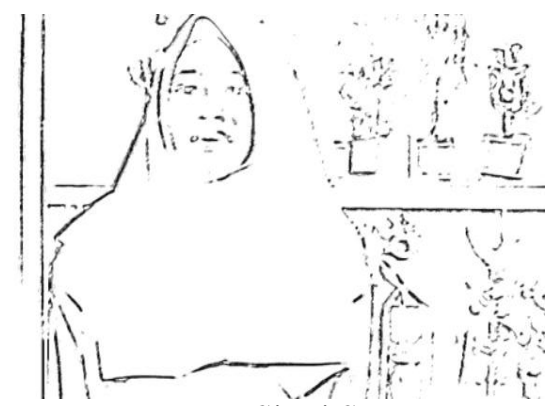

Gambar 13: Video Wawancara Siswi SMK Harapan Jaya

(Medium shoot)/ INT

Wawancara Siswi SMK Harapan Jaya

\section{Scene 12}

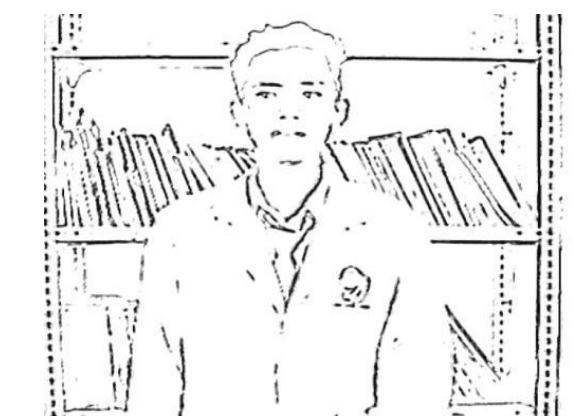

Gambar 14: Video Wawancara Siswa SMK Harapan Jaya

(Medium shoot) / INT

Wawancara Siswa SMK Harapan Jaya

\section{Scene 13}

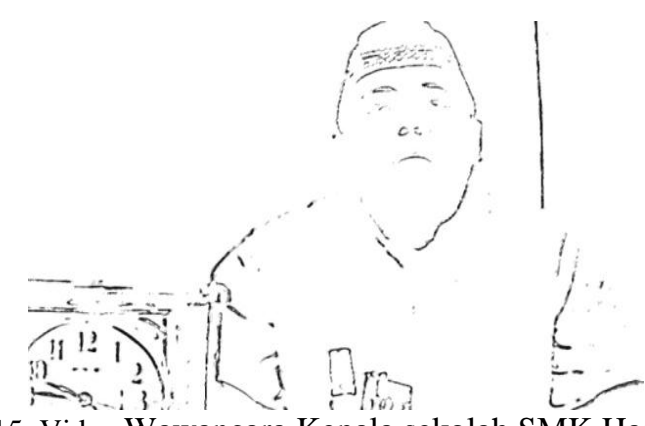

Gambar 15: Video Wawancara Kepala sekolah SMK Harapan Jaya 


\section{Wawancara Kepala sekolah SMK \\ Harapan Jaya}

\section{Scene 14}

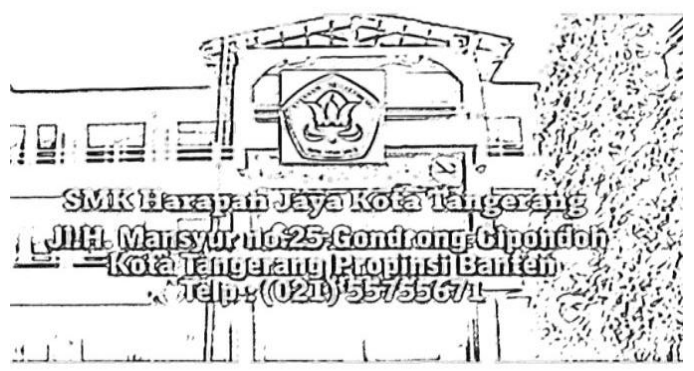

Gambar 16: Video closing Alamat Lengkap SMK Harapan Jaya Kota Tangerang

Alamat Lengkap SMK Harapan

Jaya Kota Tangerang

\section{Rundown}

\section{Gambar 17. Rundown}

\begin{tabular}{|c|c|c|c|c|c|}
\hline NO & SCENE & LOCATION & DURASI & INT/EXT & DESCRIPTION \\
\hline \hline 1 & 6 & Ruang kelas & $01: 55-02: 29$ & INT & $\begin{array}{c}\text { Suasana guru } \\
\text { sedang mengajar }\end{array}$ \\
\hline 2 & 10 & Ruang kelas & $04: 09-04: 32$ & INT & $\begin{array}{c}\text { Suasana guru } \\
\text { sedang mengajar }\end{array}$ \\
\hline 3 & 2 & Ruang Guru & $00: 20-02: 24$ & INT & Suasana ruang guru \\
\hline 4 & 13 & $\begin{array}{c}\text { Ruang Kepala } \\
\text { sekolah }\end{array}$ & $05: 24-08: 09$ & INT & $\begin{array}{c}\text { Wawancara kepala } \\
\text { sekolah }\end{array}$ \\
\hline 5 & 12 & Perpustakaan & $05: 02-05: 23$ & INT & Wawancara Siswa \\
\hline 6 & 11 & $\begin{array}{c}\text { Ruang kepala } \\
\text { sekolah }\end{array}$ & $04: 33-05: 01$ & INT & Wawancara Siswi \\
\hline 7 & 7 & $\begin{array}{c}\text { Ruang kepala } \\
\text { sekolah }\end{array}$ & $02: 29-02: 40$ & INT & $\begin{array}{c}\text { Piala yang diraih } \\
\text { SMK Harapan Jaya }\end{array}$ \\
\hline 8 & 3 & $\begin{array}{c}\text { Tulisan SMK } \\
\text { Harapan Jaya }\end{array}$ & $01: 09-01: 12$ & EXT & $\begin{array}{c}\text { Suasana gapura } \\
\text { selamat datang } \\
\text { SMK Harapan Jaya }\end{array}$ \\
\hline 9 & 4 & Gedung & $01: 13-01: 25$ & EXT & $\begin{array}{c}\text { Gedung SMK } \\
\text { Harapan Jaya }\end{array}$ \\
\hline
\end{tabular}

\section{Production}

Production adalah proses pengambilan gambar atau shootingvideo dengan bekerjasamanya antara pemain dan crew untuk pewujudan rumusan dari tahap preproduction dalam bentuk skenario, naskah, dan storyboard yang telah dibuat. Pada tahap production semua unsur teknis dan kreatif seperti naskah, actor, sinematografi dan suara bergabung dibawah pengawasan kreatif sutradara. Dalam menjalankan proses production pengambilan gambar atau shootingvideo ada beberapa hal yang harus dipersiapkan dengan baik, diataranya : desain produksi termasuk storyboard yang bisa menjadi panduan yang baik tentang hal-hal yang harus dikerjakan selama shooting, kesiapan crew dalam menjalankan perannya masing-masing dan kesiapan perlengkapan yang juga merupakan tanggung jawab masing-masing crew. 


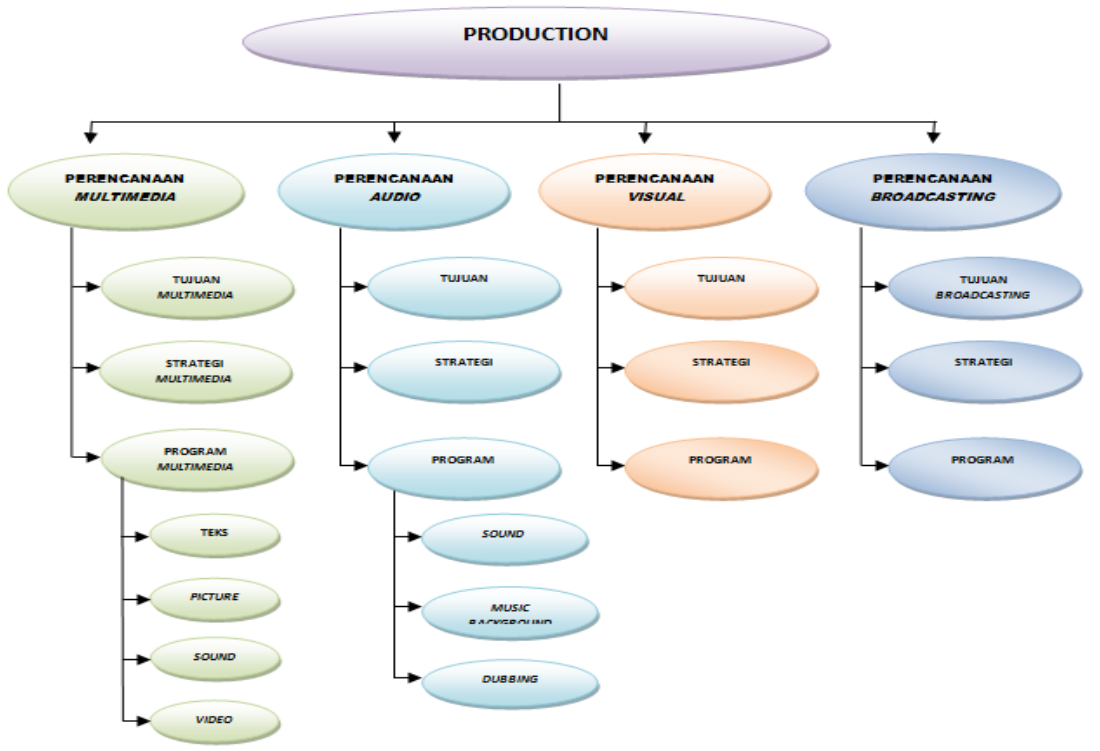

Gambar 18. Production

\section{Strategi Multimedia}

Geografi : Wilayah Kota dan Kab. Tangerang

Demografi : • Jenis Kelamin : Pria \& Wanita

- Kelas Ekonomi :

Menengah

Menengah Bawah

- Usi : 13 - 16 tahun

- Sasaran : 1. Siswa-siswi SMP / Setara

\section{Program Multimedia}

\section{Program Audio}

Setiap audio yang diterapkan untuk mengisi suara diambil dari video yang sudah dipersiapkan sesuai dengan kebutuhan dari media informasi yang dirancang, diambil dari musik mp3, dicari sound efek yang sesuai. Adanya program editing memudahkan untuk membuat audio kemudian dilakukan proses penyesuaian rancangan video yang akan disuguhkan kepada masyarakat.

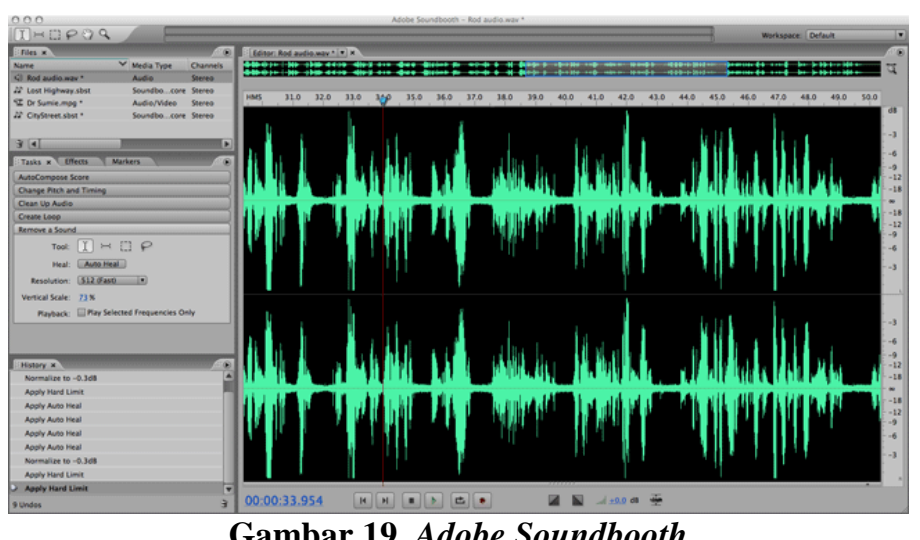




\section{Adobe Premier CS5}

Didalam proses produksi inilah perancangan spesial effects dibuat menggunakan aplikasi-aplikasi yang merupakan hasil dari kemajuan teknologi. Acuan storyboard diubah menjadi animatrix yaitu semacam slideshow dari storyboard yang sudah diisi dengan dialog yang belum diedit.

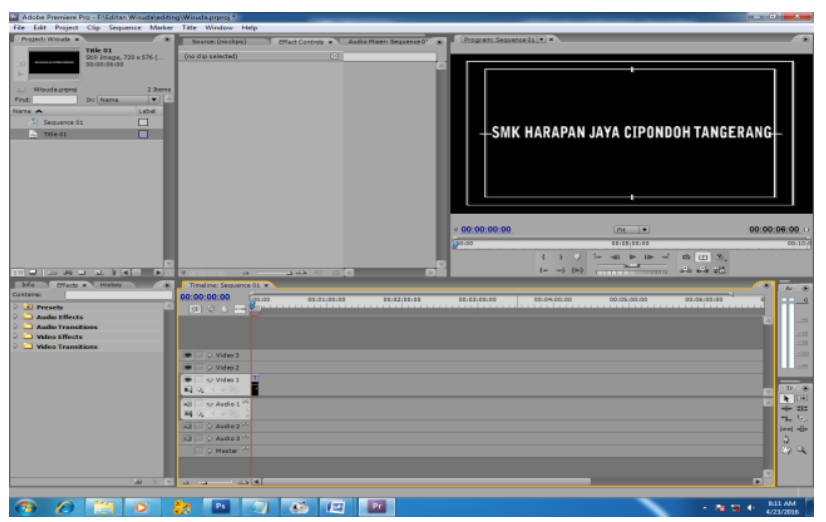

Gambar 20. Adobe Premiere Pro

\section{Corel Video Studio X5}

Corel Video Studio Pro X5 adalah definisi tugas berat video high editing software yang memungkinkan mengimpor pengguna, mengedit, membuat, ekspor dan berbagi standar mereka sendiri dan video definisi tinggi. Pengguna dapat mengekspor proyek mereka ke berbagai media termasuk DVD, VCD, Blu-Ray dan bahkan YouTube.

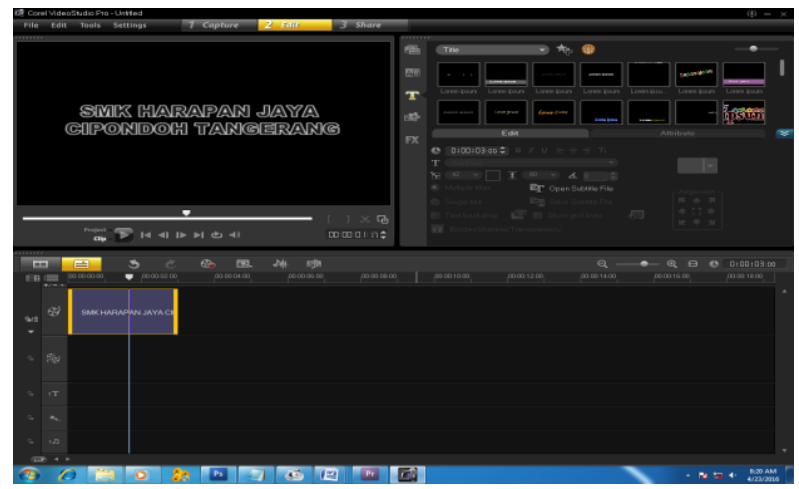

Gambar 21. Corel Video Studio X5

\section{Adobe Photoshop CS3}

suatu perangkat lunak canggih yang dapat Anda gunakan untuk membuat, menyunting dan memanipulasi tampilan termasuk mengoreksi warna dan memberi efek tampilan atas sebuah gambar atau photo, hasil dari program ini merupakan sebuah gambar / image, di dalam komputer grafis terbagi menjadi 2 kelompok yaitu Gambar Bitmap dan Gambar Vektor. 


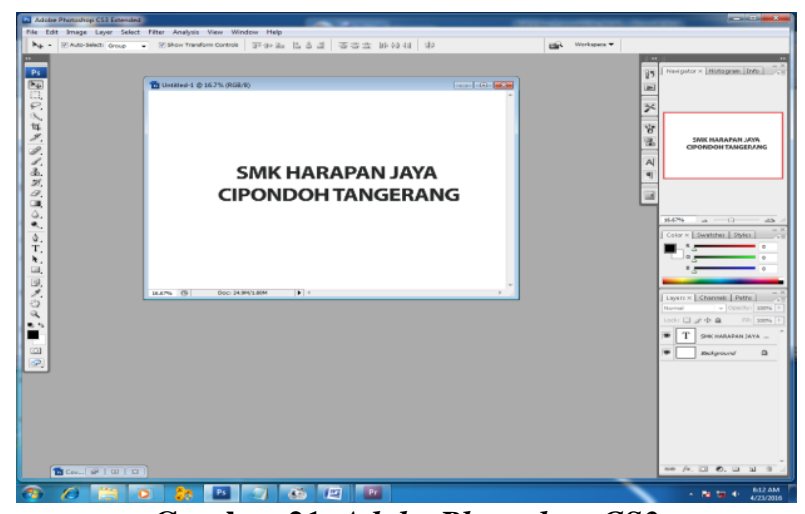

Gambar 21. Adobe Photoshop CS3

\section{Anggaran Produksi}

\begin{tabular}{|c|c|c|}
\hline No. & Alat Produksi & Keterangan \\
\hline 1. & $\begin{array}{l}\text { Kamera Panasonic HDC } \\
\text { MDH1 Full HD }\end{array}$ & $\begin{array}{l}\text { Rp } 250.000 \text { per hari } \\
@ 4 \text { hari }=\text { Rp } \\
1.000 .000\end{array}$ \\
\hline 2. & Nikon D3200 & Milik sendiri \\
\hline 3. & Tripod & $\begin{array}{l}\text { Rp } 25.000 \text { per hari } \\
@ 4 \text { hari = Rp } \\
100.000\end{array}$ \\
\hline 4. & Slider & $\begin{array}{l}\text { Rp } 50.000 \text { per hari } \\
\text { @ } 4 \text { hari = Rp } \\
200.000\end{array}$ \\
\hline 5. & Mic condenser & $\begin{array}{l}\text { Rp } 50.000 \text { per hari } \\
\text { @ } 4 \text { hari = Rp } \\
200.000\end{array}$ \\
\hline 6. & Kru produksi & $\begin{array}{l}\text { Rp } 100.000 \text { per hari } \\
@ 4 \text { hari }=\text { Rp } \\
400.000\end{array}$ \\
\hline 7. & Aktor & $\begin{array}{l}@ 4 \text { hari }=R p \\
200.000\end{array}$ \\
\hline & TOTAL & Rp 2.100.000 \\
\hline
\end{tabular}

Table 1.Anggaran Produksi

\section{Literatur Review}

1. Perancangan Video Company Profile Sebagai Media Promosi dan Informasi di SMA Institut Indonesia Semarang 2014, Semarang, adalah salah satu judul Jurnal yang dibuat oleh Ratih Devi Indriani selaku mahasiswa Sekolah Tinggi Teknologi. Penelitian ini menjelaskan tentang pembuatan video company profile sebagai media promosi dan informasi di sma institut indonesia semarang.

2. Perancangan Aplikasi Multimedia Interaktif Company Profile Generic, 2011, Garut adalah salah satu judul Jurnal yang dibuat oleh Septiana Firdaus, Dhami Johar Damiri, Dewi Tresnawati selaku mahasiswa Sekolah Tinggi Teknologi Garut. Penelitian ini menjelaskan tentang pembuatan aplikasi interaktif company profile generic.

3. Perancangan Company Profile Efrat Production Malang, 2010, Malang, adalah salah satu judul Jurnal yang dibuat oleh Ramdhani Dwi Cahya Adi, Selaku mahasiswa Universitas Negeri Malang. Penelitian ini menjelaskan tentang pembuatan video company profile Efrat production malang. 
4. Perancangan Video Company Profile Agrowisata Sondokoro Tasikmadu Karanganyar 2011, adalah salah satu judul Skripsi yang dibuat oleh Ratih Erlin Andriana Lupitasari selaku mahasiswa Universitas Nasional Informatika dan Komputer FTI UNSA. Penelitian ini menjelaskan tentang pembuatan video company profile pariwisata yang berada di karanganyar.

5. Perancangan Company Profile Berbasis Profile Berbasis Video Sebagai Media Promosi SMK Muhammadiah 1 Kepanjen, 2010, Malang, adalah salah satu judul Skripsi yang di buat oleh Fariz Setia Kusuma, selaku mahasiwi Universitas Negeri Malang. Penelitian ini menjelasan tentang Pembuatan video profile sebagai media promosi SMK Muhammadiyah 1 Kepanjen.

\section{Postproduction}

Tahap postproduction adalah proses finishing sebuah karya sampai menjadi sebuah video yang utuh dan mampu menyampaikan sebuah cerita atau pesan kepada audience. Dalam proses postproduction semua gambar yang didapat pada proses production di satukan dan di edit oleh seorang editor. Kegitan pemutaran dan distribusi juga masuk di dalam proses postproduction. Tahapan proses postproduction, yaitu :

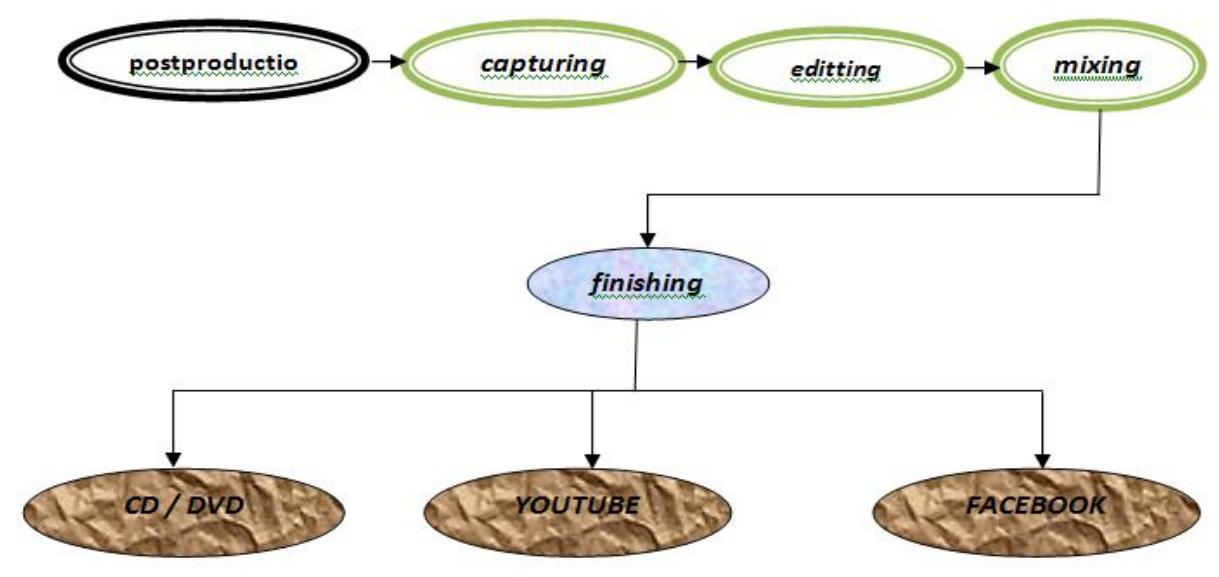

Gambar 22. Postproduksi

\section{KESIMPULAN}

Media Audio Visual sebagai media promosi dan informasi yang dikemas dalam bentuk video sangat di perlukan bagi SMK Harapan Jaya Kota Tangerang yang bertujuan meningkatkan suatu image atau citra dan memberikan informasi kepada masyarakat khususnya orang tua yang akan menyekolahkan putra dan putrinya di SMK Harapan Jaya Kota Tangerang. Pembuatan sebuah media video profile harus memperhatikan faktor-faktor yang berhubungan dengan sekolah yang bersangkutan dalam hal ini penulis menyusuaikan dengan keinginan stakeholder, mulai dari pembuatan video dan audio, tampilan, isi pesan dan penutup. Hal ini bertujuan untuk memperkuat SMK Harapan Jaya Kota Tangerang dalam mempromosikan dan menginformasikan profile sekolah. Pembuatan sebuah media audio visual yang menarik dan dapat memenuhi kebutuhan masyarakat yaitu dengan membuat sebuah video yang berisikan infomasi-informasi profile sekolah tersebut, yang berisikan dari beberapa video yang berisi teks, gambar, dan background suara dan disertakan beberapa spesial efek sehingga tampak lebih menarik. 


\section{DAFTAR PUSTAKA}

[1] Arifin, Eva. 2010. Broadcasting To Be Broadcaster, Yogyakarta : Graha Ilmu.

[2] Binanto, Iwan. 2010. "Multimedia Digital Dasar (Teori dan Pengembangannya)", Yogyakarta: Andi

[3] Hendratman, Hendi. 2012. "The Magic of Adobe After Effects", Informatika, Bandung.

[4] Liliweri. 2011.Teknik Membuat Iklan.Jakarta : Indie

[5] Pujiriyanto. 2012. Pengajaran Pemahaman melalui Desain. Jakarta : Indeks

[6] Rahardja, Untung. Sugeng Widada. Dewi Immaniar Desrianti . 2010. KPM Sebagai Pedoman Produksi Media MAVIB (Multimedia Audio Visual and Broadcasting) Journal CCIT Vol.3 No.2.

[7] Rahmawati, Indah. 2011. "Menjadi Sutradara Televisi : dengan Single dan Multi Camera". Jakarta: Grasindo.

[8] Yakub. 2012.PengantarSistemInformasi Yogyakarta : Graha Ilmu 